\title{
A Within-Individual Examination of the Predictors of Gun Carrying During Adolescence and Young Adulthood Among Young Men
}

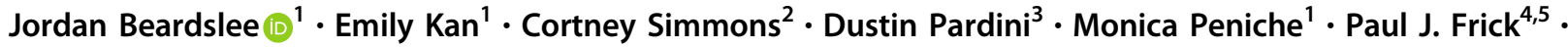 \\ Laurence Steinberg ${ }^{6,7} \cdot$ Elizabeth Cauffman ${ }^{1}$
}

Received: 27 January 2021 / Accepted: 17 June 2021 / Published online: 16 July 2021

(c) The Author(s) 2021

\begin{abstract}
Although prior studies have identified several risk factors for gun carrying, no prior longitudinal studies have examined a comprehensive set of explanatory factors together in within-individual change models or examined whether the predictors of gun carrying change across adolescence and early young adulthood. The present study fills these gaps by examining the predictive utility of several risk factors for gun carrying, and by examining whether any of the associations vary by age. The sample included 1216 young men who were arrested for the first time during adolescence (approximately 15 years old) and interviewed regularly for 5 years (until approximately 20 years old) after the first arrest. The outcome was youth-selfreported gun carrying and the risk factors included several variables consistent with various explanations for gun carrying (psychosocial maturity deficits; antisocial behavioral style; socialization; victimization). Research questions were addressed with fixed effects dynamic panel models (within-individual change models). Results showed that the most robust predictors of gun carrying were increased exposure to guns and gun-related violence and increased engagement in other antisocial and illegal behavior. The results emphasize the specific etiology of gun carrying and the potential social contagion effect of gunrelated events. Overall, the study points to the need for prevention and intervention programs to specifically target the reduction of the real and perceived prevalence of gun-related events in young men's lives.
\end{abstract}

Keywords Gun carrying $\cdot$ Risk factors $\cdot$ Firearm carrying $\cdot$ Adolescent offending

\section{Introduction}

Supplementary information The online version contains supplementary material available at https://doi.org/10.1007/s10964021-01464-6.

Jordan Beardslee

jbear@uci.edu

1 Department of Psychological Science, University of California, Irvine, CA 92697-7085, USA

2 Department of Psychology, Yale University, New Haven, USA

3 School of Criminology and Criminal Justice, Arizona State University, Tempe, USA

4 Department of Psychology, Louisiana State University, Baton Rouge, USA

5 Institute for Learning Sciences \& Teacher Education, Australian Catholic University, Brisbane, Queensland, Australia

6 Department of Psychology, Temple University, Philadelphia, USA

7 King Abdulaziz University, Jeddah, Saudi Arabia
Adolescents and young adults who carry firearms put themselves and those around them at risk for violent injuries and death (Branas et al., 2009; Carter et al., 2013; Loughran et al., 2016; Pickett et al., 2005). As such, it is critical to identify the factors that place youth most at risk for gun carrying. Although some studies have focused on risk factors that are related to the individual, such as deficits in psychosocial maturity (Lee et al., 2020) or engaging in other antisocial and illegal behaviors (Docherty et al., 2019a, 2019b), other studies suggest that the primary reasons for youth gun carrying are contextual, such as socialization processes (Wilkinson et al., 2009) or self-protection after victimization (Oliphant et al., 2019). In addition, given the many developmental and social differences between adolescents and young adults, it is possible that the predictors of gun carrying change with age. Unfortunately, no prior longitudinal study has examined a comprehensive set of risk factors together, particularly while controlling for youths' prior propensity to carry a gun, or examined 
whether the salience of the risk factors for gun carrying changes across adolescence and the transition to young adulthood. The present study addresses these gaps by simultaneously examining the associations between several potential explanatory factors and gun carrying, and by examining whether the magnitude of these associations changed with age.

\section{Prevalence and Seriousness of Gun Violence and Gun Carrying in the United States}

Gun violence is a serious public health issue in the United States. During the recent decade (2010-2019), over 350,000 people in the United States died as a result of gun violence, which resulted in over 8 million years of life lost (Centers for Disease Control, 2021b). It is now well documented that gun violence disproportionately impacts young men (Oliphant et al., 2019). Males account for approximately $85 \%$ of all deaths related to gun violence (Centers for Disease Control, 2021a), and in 2019, over 3800 15-to-24-year-old men were killed by guns (excluding suicide and unintentional death; Centers for Disease Control, 2021b). Moreover, more than $71 \%$ of these victims were young men of color (Centers for Disease Control, 2021b). Indeed, firearm homicide was the leading cause of death for 15-to-24-yearold Black males in 2019 (Centers for Disease Control, 2021b).

Gun carrying, a common precursor to gun violence (Pardini et al., 2020), is also fairly common in the United States. Approximately 5-10\% of community youth report carrying a gun in the past year (Centers for Disease Control, 2012; Oliphant et al., 2019) and approximately $20 \%$ of (somewhat high risk) adolescents report carrying a gun during adolescence (Beardslee et al., 2019). One study of adolescents convicted of serious offenses found that almost half $(46 \%)$ of the sample carried a gun during the 7-year study period and almost a quarter (23\%) engaged in gun violence during this time period (Pardini et al., 2020). Another study with detained youth found that approximately $73 \%$ had used a firearm prior to age 18 (Teplin, 2019). Given the high prevalence and catastrophic consequences associated with gun violence, particularly for young men of color, it is critical to identify the risk factors that may lead young men to carry (and potentially use) guns.

\section{Potential Explanations for Gun Carrying During Adolescence and Young Adulthood}

Researchers studying the risk factors for gun carrying generally focus on characteristics about the individual (e.g., history of aggression/illegal activity; impulsivity) or the context to which the individual is exposed (e.g., victimization; peer delinquency; for reviews, see Oliphant et al., 2019; Schmidt et al., 2019). Studies examining developmental change in gun carrying generally find that gun carrying tends to be less stable and more episodic than other illegal behavior (Dong \& Wiebe, 2018; Steinman \& Zimmerman, 2003), and that the prevalence of gun carrying and gun violence generally peak during the early $20 \mathrm{~s}$ (Beardslee et al., 2018; Pardini et al., 2020). As such, it is critical to identify the time-varying within-individual risk factors that explain why an adolescent or young adult may carry a gun in some years but not others.

\section{Deficits in psychosocial maturity}

Youth may carry guns because of diminished psychosocial maturity, which encompasses several aspects of development (e.g., impulse control; future orientation) that influence adolescent decision-making (Greenberger \& Sørensen, 1974; Steinberg \& Cauffman, 1996). An adolescent boy who is unable to consider the long-term consequences of his actions or control antisocial impulses may be more likely to carry a gun because he is not thinking (or does not care) about the potential danger he could inflict or the legal troubles he could encounter. While many prior studies have found significant associations between components of psychosocial maturity (e.g., impulsivity) and serious offending in general (Bechtold et al., 2014; Fine et al., 2016; Monahan et al., 2013), only a few longitudinal studies have looked at psychosocial maturity specifically in relation to firearm usage (see Lee et al., 2020; Pardini et al., 2020; Rowan et al., 2019). For example, one study with a relatively high-risk community sample found that future orientation may mediate the between-person associations between exposure to violence and subsequent gun carrying (Lee et al. 2020). Furthermore, a study of serious adolescent offenders found that low future orientation was a robust predictor of gun violence in between-individual models but not within-individual models, suggesting that selection effects or omitted confounding variables may have accounted for the between-individual effects (Rowan et al. 2019). As such, it is not clear whether changes in psychosocial maturity would relate to within-individual changes in gun carrying.

\section{Antisocial behavioral style}

A broad preference for engaging in antisocial behavior, which may include the tendency to engage in a variety of antisocial and illegal behaviors, may increase the likelihood that youth carry guns. Indeed, prior work suggests that the majority of offenders-especially young offenders-do not specialize in certain types of illegal behavior (Piquero, 2000; Simon, 1997). This suggests that engaging in one 
type of illegal behavior, such as theft, may lead to (or facilitate) another, such as gun carrying. For example, prior studies of justice-system-involved and community youth have consistently found that drug dealing (Docherty et al., 2019a, 2019b; Lizotte et al., 2000; Vaughn et al., 2012), theft/property offending (Vaughn et al., 2019), aggressive/ violent offending (Docherty et al., 2019a; Spano, 2012), and conduct/externalizing problems (Loeber et al., 2004; Vaughn et al., 2016) are significantly related to gun carrying and gun violence. For example, one study with adolescents convicted of serious offenses used within-individual change models with 84 consecutive months of data and found a strong and consistent association between drug dealing and gun carrying (Docherty et al., 2019b). Specifically, the study found that gun carrying increased slightly before a drug dealing episode, increased dramatically during the month of drug dealing, and declined rapidly after the drug dealing episode ended but remained higher than initial levels (Docherty et al., 2019b). Although the robust withinperson association between drug dealing and gun carrying was compelling in this study, this study did not include measures of psychosocial maturity, parental gun carrying, parent non-gun carrying, or prior gun carrying, and this study was focused on understanding the predictors of gun carrying in a relatively high risk sample of serious adolescent offenders.

Nonetheless, adolescents may be more likely to carry guns during years when they engage in other types of offending because guns may facilitate or support other antisocial goals and activities. Because most of the longitudinal studies in this area tested the antisocial behavior explanation with between-individual models, the extent to which these factors can be used to understand withinindividual fluctuations in gun carrying is less understood.

\section{Social influence or contagion effect}

Exposure to delinquent or gun carrying peers and parents may also increase youths' odds of gun carrying. Consistent with a socialization or social influence hypothesis, youth may be directly and indirectly taught or encouraged to carry guns by close members of their social network (i.e., peers, parents). Indeed, several studies found that having peers who carry guns (Cao et al., 2008; Hemenway et al., 2011; Lizotte et al., 2000; Robertson et al., 2020) is a significant risk factor for gun carrying and other violence. One study of adolescent and young adults convicted of violent offenses, $92 \%$ of whom reported having a gun, found that over $95 \%$ of participants reported having peers who carried guns, and over $78 \%$ had peers who used guns to commit crimes (Wilkinson et al., 2009).

In addition, significant associations between general and non-gun peer delinquency with gun carrying (e.g., Keil et al., 2020) suggest that antisocial peers may contribute to gun carrying by potentially increasing access to illegal guns or by encouraging antisocial behaviors in general- even if they do not specifically carry guns themselves. In addition to peers, parents are also important socializing agents. Although researchers have examined a variety of parenting factors in relation to youth antisocial behavior and offending (Barnes et al., 2006; Guo et al., 2002; Johnson et al., 2011; Van Ryzin et al., 2012), the extent to which an adolescent or young adult's parent's gun carrying and general offending are associated with his own gun carrying is unclear. However, results of prior studies indicate that having "guns in the home" is a significant risk factor for youth gun carrying (e.g., Molnar et al., 2004), suggesting that parent gun carrying may be an important factor for understanding youth gun carrying.

\section{Victimization}

One unfortunate reality is that many youth in the United States, particularly justice-system-involved youth, are exposed to serious violence. In fact, one study estimated that almost $10 \%$ of justice-system-involved male youth in Chicago were injured by a gun prior to age 18 and nearly $33 \%$ of the sample had been injured or killed by a firearm prior to approximately age 32 (Teplin, 2019). Another study that followed youth after their first contact with the justice system found that nearly $39 \%$ of youth were shot or saw someone else get shot during the 5 years after their first arrest (Shulman et al., 2021). Similar to justice-system-involved samples, youth in low income neighborhoods are also at an elevated risk of being exposed to gun violence. One study found that approximately $16 \%$ of adolescent and young adults in a lower income neighborhood in Connecticut witnessed someone being shot in their lifetime (Santilli et al., 2017).

One possible reason that adolescents and young adults may carry guns is for self-protection or retaliation (Oliphant et al., 2019). In line with this explanation, youth who experience or witness gun and/or non-gun violence are potentially at risk for gun carrying because of a desire to protect themselves from future attacks or because of a desire to retaliate against their attackers (Kleck \& Gertz, 1998; Sheley \& Wright, 1993; Spano \& Bolland, 2013; Spano et al., 2010). One published review on the predictors of gun carrying supported this hypothesis by finding that retrospective reports of a desire for self-protection was one of the most consistent predictors of gun carrying (see Oliphant et al., 2019). Additional support for the self-protection/ retaliation hypothesis has been found in a variety of studies with justice-system-involved and community youth. For example, prior studies with within-person and betweenperson models have found that exposure to gun violence (Beardslee et al., 2019; Sumner et al., 2016), exposure to 
non-gun violence (Rowan et al., 2019), and exposure to general violence (Pardini et al., 2020; Reid et al., 2017; Spano, 2012; Spano \& Bolland, 2013) are significantly related to gun carrying and gun violence among adolescents and young adults.

\section{Demographic factors related to gun carrying}

As mentioned throughout the introduction, there are demographic factors that have been associated with gun carrying. One such factor is age: gun carrying tends to gradually increase throughout adolescence and early young adulthood, often peaking during the early $20 \mathrm{~s}$. Furthermore, gun carrying and gun violence are both disproportionately higher among males and among justice-system-involved youth (Oliphant et al., 2019). Many studies also find that gun violence is concentrated in urban, metropolitan, and lower socioeconomic neighborhoods (Oliphant et al., 2019). Although prior workst suggests race differences in the prevalance of gun carrying, conflicting findings have been reported based on geography (i.e., urban versus rural; Oliphant et al., 2019).

\section{Limitations In Prior Work}

Although prior studies identified several important risk factors for gun carrying, there are many limitations in the existing body of work. First, no prior study simultaneously examined all of the potential explanatory while also controlling for the youths' prior gun carrying. Of the existing longitudinal studies in this area, most studies focused on specific risk factors such as exposure to violence (Beardslee et al., 2018; Spano \& Bollard, 2013), drug dealing (Docherty et al., 2019b; Lizotte et al., 2000), peer delinquency (Docherty et al., 2019a; Lizotte et al., 2000), conduct problems/aggressive behavior (Docherty et al., 2019a; Spano, 2012), or neighborhood/socio-economic status (Beardslee et al., 2021; Docherty et al., 2019a). None of these studies controlled for all the other relevant behavioral, psychosocial, and contextual factors. While one study included prior gun carrying as a covariate, this study utilized between-individual models to examine perpetrated gun violence and did not control for future orientation, exposure to gun violence, or parental gun carrying and non-gun offending (Pardini et al., 2020). Another longitudinal study with the same sample of serious adolescent offenders as Pardini and colleagues (2020) examined the predictors of gun violence (not gun carrying), but did not control for prior gun carrying, exposure to gun violence, peer gun carrying, impulse control, or parental gun carrying and non-gun offending (Rowan et al., 2019).

Additionally, it is unknown whether the predictors of gun carrying change with age. Given that prior studies have found age differences in the predictors of other types of antisocial behavior (Fergusson et al., 2002; Monahan et al., 2009), it is important to examine whether the nature of the risk factors for gun carrying changes with age. Indeed, there are many cognitive, socio-emotional, and contextual differences between adolescents and young adults, and these differences may impact the degree to which risk factors are related to gun carrying. For example, developmental immaturities during adolescence may render adolescents more susceptible to adverse contextual experiences than adults. In addition, the most salient source of social influence may change across development. While parents' behavior may have greater influence during early adolescence, peers may be more influential in late adolescence and early young adulthood. There is some evidence of potential age differences in the predictors of gun carrying, but existing studies are limited by their comparison of juveniles to adults (Decker et al., 1997; Watkins et al., 2008) or their utilization of between-individual statistical models and a limited set of explanatory factors (Lizotte et al., 2000).

\section{The Current Study}

The present study was designed to overcome the limitations in prior work by testing whether several psychological, behavioral, and contextual risk factors were associated with gun carrying during adolescence and early young adulthood. Risk factors in the four primary domains (psychosocial maturity, behavioral, social influence, victimization) were examined simultaneously to identify the strongest predictors of gun carrying. Analyses also controlled for other potential explanatory factors and youths' prior propensity to carry a gun. The present study was also able to examine the main effects of relevant time-stable demographic factors, such as age at first arrest (i.e., time 1) and race/ethnicity. It is important to examine all factors together given that many of the factors are likely related (i.e., individuals with a proclivity for antisocial behaviors may also associate with like-minded peers). Considering the many differences between adolescence and young adulthood, the present study also examined whether the nature of the associations between the risk factors and gun carrying changed with age.

Given that gun violence is disproportionately higher among males and justice-system-involved youth (Oliphant et al., 2019), the research questions were addressed using data drawn from a 5-year longitudinal study of young men who had a history of law-breaking behavior and were housed predominately within the community. The moderately high-risk nature of the sample ensured that there was sufficient within-person variability in gun carrying across the study period, which allowed the use of fixed effects 
dynamic panel models to estimate within-individual change in the likelihood of gun carrying. Within-individual change models are advantageous because they treat individuals as their own control variables, which means that all unchanging factors about individuals and their environments are automatically controlled (Allison, 2009). As such, these models reduce the potential impact of selection effects, shared risk factors, and confounding variables, and offer stronger tests of potential causal pathways than traditional between-individual models. By focusing exclusively on within-individual change, the analysis sought to understand why a person carries a gun in some years but not others. This is a fundamentally different question than one that asks why one person carries a gun at all, but another person never does-which is typically the question that can be answered with traditional between-individual models (which is an interesting question but can be confounded by the many differences between the types of people who do and do not carry guns).

\section{Methods}

\section{Participants}

The sample included the 1216 male youth enrolled in the Crossroads Study (http://sites.uci.edu/crossroadsinfo/; see Cauffman et al., 2021). Youth were eligible to participate in the Crossroads Study if they were recently arrested for the first time for a low or moderate offense (e.g., vandalism; theft; mostly misdemeanors), were between 13 and 17 years old, and were being processed in Philadelphia, Pennsylvania $(N=533)$; Orange County, California $(N=532)$; or Jefferson Parish, Louisiana $(N=151)$. The study investigators selected these three locales to enhance the diversity and representativeness of the sample. The combined sample was racially and ethnically diverse: $46 \%$ Latinx/Hispanic, $37 \%$ Black/African American, 15\% White, and 2\% selfidentified as multi-racial, multi-ethnic, or another race or ethnicity. Of those who were contacted, approximately $72 \%$ agreed to participate in the study.

\section{Procedures}

Researchers identified potential study participants through a collaborative process with the probation departments and courts in each site. From 2011 to 2013, courts and/or probation departments provided research staff with a list of juveniles who were arrested in the past week and research staff determined whether each juvenile met the criteria for study inclusion (e.g., eligible charge; within age range; no prior history of arrests). After researchers identified the eligible youth, research staff contacted youth and their parents via the telephone, email, or a house visit within six weeks of case dispositions. All contact information was obtained from the probation department, court records, and/ or publicly accessible information sources.

Eligible youth and their families were informed of the nature of the study and invited to participate. Youth who were interested in the study underwent an extensive parent-consent and youth-assent process, which included a detailed description of the study along with a description of the Department of Justice's Privacy Certificate. The advantage of the Privacy Certificate was that all data obtained as part of the Crossroads study were protected against subpoenas, court orders, and/or other involuntary disclosures. The only exceptions to the promise of confidentiality were instances where the participant revealed suicidal thoughts, homicidal thoughts, or serious plans to engage in future criminal conduct.

Project staff interviewed participants using a secure, computer-assisted program. Interviews were about 2 to $3 \mathrm{~h}$ and were conducted in the community or wherever the youth was housed (e.g., detention center; jail). Phone interviews were conducted when participants were not physically accessible (e.g., moved out of state). Youth completed their first interview (i.e., "baseline"; time 1) within six weeks of receiving the disposition for the charges associated with their first arrest. After the baseline interview, Crossroads research staff members interviewed participants biannually for three years and then annually for two years (baseline plus biannual/ annual interviews over a 5-year period; 9 total measurement occasions). Youth were between 13 and 17 years of age $\left(M_{\text {age }}=15.29\right)$ at baseline and between 18 and 23 years of age $\left(M_{\text {age }}=20.29\right)$ at the 5-year follow up interview. Slightly more than half of all interviews were conducted in participants' homes (52\%). The remaining interviews were conducted in coffee shops or somewhere in the community $(36 \%)$, on the phone $(6 \%)$, in detention, jail, or other locked facilities $(5 \%)$, or in participants' friends' or family members' homes (1\%). Interviews assessed a variety of domains, including participants' thoughts, behaviors, attitudes, and contextual experiences. The variables used in the present analysis were self-reported by the youth at all 9 interviews. Retention across the 5-year study was high: between $85 \%$ and $95 \%$ of the initial sample completed each of the follow up interviews (missing data discussed below).

The research team utilized many strategies to prevent attrition. For example, at the end of each interview, participants were asked to provide all available contact information for themselves and for friends and family members who might know how to contact the youth in the future. Additionally, the research team was flexible when scheduling the interviews. Interviewers were able to meet participants wherever and whenever was most convenient for the participant. Youth were also financially compensated for their time according to an escalating payment 
plan. The Institutional Review Board at the participating universities approved all recruitment and study procedures. More detailed information about the Crossroads study has been published previously (Cauffman et al., 2021).

\section{Measures}

\section{Gun carrying}

At each interview, one item from the Self-Report of Offending scale (SRO; Huizinga et al., 1991) was utilized to assess whether the participant had carried a gun since the previous interview $(1=$ yes, carried a gun; $0=$ no, did not carry a gun). It was assumed that participants who reported shooting another person during the recall period had also carried a gun. Gun carrying was re-coded to "missing" for periods during which the participant was housed in a secure, locked facility (e.g., juvenile hall or local jail) for the entire recall period because it is unknown whether a participant would have carried a gun in that recall period given that the facility would have prohibited access to one ( $<2 \%$ of interviews).

\section{Psychosocial maturity}

Impulse control A measure of impulse control was derived from the Impulse Control scale from the Weinberger Adjustment Inventory (Weinberger \& Schwartz, 1990). The Impulse Control scale consisted of 8 items that measured the extent to which the participant was generally able to inhibit impulsive behavior. Youth responded to each item using a 5point Likert scale that ranged from 1 ("false") to 5 ("true"). Sample items include behaviors such as, "I do things without giving them enough thought" (reverse scored) and "I say the first thing that comes into my mind without thinking enough about it" (reverse scored). A total impulse control was created by calculating the mean of the 8 items, with higher scores indicative of a greater ability to control impulsive behavior. Internal consistency for impulse control was acceptable: mean $\alpha=0.770$, range $\alpha=0.741$ to 0.790 .

Future orientation A measure of future orientation was obtained using 15 items from the Future Outlook Inventory (Cauffman \& Woolard, 1999, unpublished manuscript). Each item asked youth to state the degree to which a statement reflected their beliefs about the future. Sample items include "I will keep working at difficult, boring tasks if I know they will help me get ahead later" and "I think about how things might be in the future." Youth responded to each item using a 4-point Likert scale that ranged from 1 ("never true") to 4 ("always true"). A total measure of future orientation was calculated by summing the 15 items, with higher scores indicating a greater orientation toward the future. Internal consistency for future orientation was acceptable: mean $\alpha=0.712$, range $\alpha=0.657$ to 0.743 .

\section{Behavioral}

Prior gun carrying As described previously, one item from the SRO (Huizinga et al., 1991) was used to measure whether the participant carried a gun during the recall period. For the primary analysis, gun carrying during the prior year (Time-1) was used as a time-varying covariate.

Non-gun theft and property offending Nine items from the SRO were used to measure non-gun related theft and property offending, which included behaviors such as vandalism, shoplifting, and joyriding. For each item, participants were asked whether they had engaged in the behavior during the recall period. The nine items were combined to create a single binary measure of theft and property offending $(1=$ yes engaged in at least one theft or property offense; $0=$ did not engage in any theft or property offending). Consistent with gun carrying, theft and property offending was set to "missing" for periods during which the participant was housed in a secure, locked facility for the entire recall period.

Non-gun aggressive and violent offending Four items from the SRO were used to measure non-gun related aggressive and violent offending, which included behaviors such as assault, fighting, and robbery. For each item, participants were asked whether they had engaged in the behavior during the recall period. If the participant engaged in any of the four behaviors, the non-gun aggressive and violent offending variable was coded as a " 1 ." If the participant did not engage in any non-gun aggressive and violent offending, the participant received a score of " 0 " for this variable. Consistent with gun carrying, aggressive and violent offending was set to "missing" for periods during which the participant was housed in a secure, locked facility for the entire recall period.

Drug dealing Drug dealing was measured with 2 items from the SRO scale (Huizinga et al., 1991). At each interview, researchers asked youth whether they had sold marijuana and whether they had sold other illicit drugs during the recall period. The 2 items were combined to create a single measure of drug dealing $(1=$ any drug dealing; $0=$ no drug dealing) at each time-point.

\section{Social influence}

Peer gun carrying Peer gun carrying was measured with a single item from the Association with Deviant Peers scale 
(Thornberry et al., 1994). The item asked youth to state the proportion of friends who had carried a gun during the recall period. Youth responded to the item using a 5-point Likert scale that ranged from 1 ("none of them") to 5 ("all of them").

Peer general (non-gun) offending Peer general offending (exclusive of gun use items) was based on a subset of items from the Association with Deviant Peers scale (Thornberry et al., 1994). At each interview, 8 items asked the participant to state the proportion of friends who had engaged in different delinquent and antisocial activities during the recall period. Youth responded to each item using a 5-point Likert scale that ranged from 1 ("none of them") to 5 ("all of them"). Sample behaviors include property damage, physical violence/fighting, burglary/ theft, and drug dealing. A total peer general offending scale was created by calculating the mean of the 8 items, with higher scores indicative of greater exposure to delinquent peers. Internal consistency for peer general offending was high: mean $\alpha=0.863$, range $=0.848$ to 0.881 .

Parent gun carrying Parent gun carrying was measured at each time-point with a single item from a modified version of the Association with Deviant Peers scale (Thornberry et al., 1994). Specifically, a single item measured whether either of the youth's parents had carried a gun during the recall period $(1=$ paternal or maternal guardian carried a gun; $0=$ neither parent carried a gun).

Parent general (non-gun) offending The research team measured parent general offending (exclusive of gun items) with 8 items from a modified version of the Association with Deviant Peers scale (Thornberry et al., 1994). For each item that was used to measure peer general offending, a parallel item asked whether either of the youth's parents had engaged in the behavior during the recall period $(1=$ one or more parent engaged in behavior; $0=$ neither parent engaged in behavior). Similar to peer general offending, sample behaviors include property damage, physical violence/fighting, burglary/theft, and drug dealing. The final parent general offending variable was a binary variable that indicated whether the participants' parents engaged in any of the general non-gun offending items during the recall period $(1=$ paternal or maternal guardian engaged in at least one general non-gun offense; $0=$ neither parent engaged in non-gun offending).

\section{Victimization}

Exposure to gun violence The research team used four items from the Exposure to Violence (ETV) inventory (Selner-O'Hagan et al., 1998) to measure exposure to gun violence during each recall period. At each interview, items measured whether the participant was shot (i.e., shot and hit) or shot at (i.e., shot at but bullet missed), and whether he witnessed someone else get shot or shot at. The four items were combined to create a single binary variable indexing whether the participant was the victim or witness of gun-related violence during each recall period $(1=$ witness/victim of gun violence; $0=$ did not experience or witness gun violence).

Exposure to general (non-gun) violence Six items from the ETV inventory (Selner-O'Hagan et al., 1998) were used to measure the degree to which the participant was exposed to non-gun violence during each recall period. At each interview, the participant reported whether he experienced or witnessed three specific (non-gun) violent events. Sample non-gun violent events include whether the participant was chased/beaten up/attacked and whether the participant witnessed someone else getting chased/beaten up/attacked. A dichotomous variable was created to index whether participants experienced any of the general (non-gun) violent events during each recall period $(1=$ victim or witness of general violence; $0=\operatorname{did}$ not experience or witness any general violence).

\section{Time-Stable Demographic Factors}

Age Youth's age at baseline/time 1 was calculated based on the date of the interview and the youth's date of birth.

Race and ethnicity Participants reported their race and ethnicity at the first interview. Race/ethnicity was coded into a 4-categories: White, Black, Hispanic, and Bi-racial/Other.

Parent highest education Parent highest education was used as a proxy for socioeconomic status. Youth reported their parent's highest education by using a 10-point scale that ranged from some grade school to professional or graduate degree.

IQ proxy A proxy for IQ was created with the vocabulary and matrix reasoning subscales of the Wechsler Abbreviated Scale of Intelligence (Wechsler, 1999).

\section{Plan of Analysis}

Research questions were addressed with dynamic panel models in fixed effects binary logistic regressions within a structural equation framework (Bollen \& Brand, 2010; Williams et al., 2018). These models are ideal for the current study because they can be used to understand within-individual change in an outcome variable, which controls for all time-stable effects of time-stable confounding variables. These models are also advantageous 
compared to traditional fixed effects models because it is possible to obtain (random effect) estimates for timestable variables (such as race or age at baseline) and control for prior levels of the dependent variable. The general specification for the time-varying, withinindividual change component of the primary model was (Allison, 2009):

GunCarrying $_{\text {it }}=\beta_{1}$ ImpulseControl $_{\text {it }}+\beta_{2}$ FutureOrientation $_{\text {it }}+\beta_{3}$ PriorGunCarrying $_{\mathrm{i}, \mathrm{t}-1}+\beta_{4}$ NonGunTheftProp $_{\text {it }}+\beta_{5}$ NonGunAggViolence $_{i t}+\beta_{6}$ DrugDealing $_{\text {it }}+\beta_{7}$ PeerGunCarry $_{\text {it }}+\beta_{8}$ PeerNonGunOffending ${ }_{i t}+$ $\beta_{9}$ ParentGunCarry $_{i t}+\beta_{10}$ ParentNonGunOffending $_{i t}+$ $\beta_{11}$ ETVGun $_{\text {it }}+\beta_{12}$ ETVNonGun $_{\text {it }}+\gamma \quad$ Demographics $_{\mathrm{i}}+\alpha_{\mathrm{i}}$ $+\mu_{\mathrm{t}}+\varepsilon_{\mathrm{it}}$

Where:

- Gun Carrying it represents the probability of carrying a gun at time $t$ for individual $i$.

- $\beta_{1}-\beta_{12}$ represents the association between the risk factor and gun carrying

In the primary models, all coefficients $\left(\beta_{1^{-}} \beta_{12}\right)$ were constrained to be equal across time. Additional models examined whether relaxing this constraint improved model fit.

- $\gamma_{\mathrm{i}}$ represents the combined effect of the time-invariant demographic factors (these are essentially random effects)

- $\quad \alpha_{\mathrm{i}}$ represents a fixed constant indexing the underlying probability of gun carrying across the time series for each individual $\mathrm{i}$

- $\mu_{\mathrm{t}}$ represents a fixed constant for each time-point (which accounts for changes in gun carrying over time)

- $\varepsilon_{\text {it }}$ represent a residual variance for individual $\mathrm{i}$ at time $\mathrm{t}$

After the primary models, the authors examined whether the magnitude of any of the associations between the risk factors and gun carrying changed during the study period. Because there is not a straightforward way to examine age interactions in these models, two strategies were utilized in the present study. First, the authors compared the primary model (which had time-invariatn effects of the risk factors) to models where each risk factor was freely estimated across time using log likelihood chi-square tests. A constrained and freely estimated model was compared for each risk factor, while controlling for all other risk factors from the primary model. In these models, a significant log likelihood chisquare test revealed that the unconstrained model may be a better fit to the data than a constrained model. Because these models may capitalize on chance when identifying fluctuations in parameter estimates over time, the authors also estimated interactions between age at time 1 and all of the primary risk factors.
As a supplemental analysis, the primary model was repeated with the three non-gun antisocial behavior and offending items as the outcomes. These analyses were conducted to evaluate whether the predictors of gun carrying were similar to the predictors of other types of antisocial behavior and offending. In particular, these models were used to predict non-gun theft and property offending, non-gun aggressive and violent offending, and drug dealing. All risk factors used in the primary models were used to predict the non-gun offending items. Gun carrying was also used as a predictor. The supplemental models also included the lagged dependent variable (consistent with the primary models).

Finally, two sensitivity analyses were conducted. In the first model, the three variables that were dichotomized in the primary analysis (non-gun theft and property offending, non-gun aggressive and violent offending, and parent non-gun offending) were left in their original forms (variety score counts). In the second model, the primary analysis was conducted without the imputed datasets (imputed data discussed below). All models in the present study were estimated with maximum likelihood estimation and conducted in Mplus version 8 with 25 imputed datasets (discussed below).

\section{Missing Data}

Crossroads study participants completed over $92 \%$ of all possible interviews ( 9 total interviews X 1216 participants $=10,944$ possible interviews), resulting in over 10,000 data points for possible inclusion in the present study. Of the missing interviews (approximately $8 \%$ of all interviews), the primary reason for missing data was because the research team was unable to contact or locate the participant during the search window $(41.7 \%$ of missed interviews). Only $24 \%$ of missed interviews were because the participant withdrew from the study, $10 \%$ of missed interviews were due to chronic no-shows which resulted in an expired search window, and $9 \%$ of missed interviews were because a legal actor (e.g., lawyer, justice system facility staff) prevented us from contacting/accessing the participant, and the rest were missed due to other reasons (e.g., military deployment, death, hospitalization).

Of the 9 possible interviews for each participant, $71 \%$ of the participants missed none of the interviews, $15 \%$ missed one interview, 5\% missed two interviews, 3\% missed three interviews, and $6 \%$ missed four or more interviews. The authors examined whether having missing data was associated with any of the study variables measured at baseline using binary logistic regressions. These analyses revealed that having missing data was slightly more likely among Black than White $(p=0.024)$ and Hispanic $(p<0.001)$ youth, among those with lower IQs 
Table 1 Descriptive statistics for time-varying study variables by time

\begin{tabular}{|c|c|c|c|c|c|c|c|c|c|}
\hline Study Variable & $\begin{array}{l}\text { Time } 1 \\
M(S D) / \%\end{array}$ & $\begin{array}{l}\text { Time } 2 \\
M(S D) / \%\end{array}$ & $\begin{array}{l}\text { Time } 3 \\
M(S D) / \%\end{array}$ & $\begin{array}{l}\text { Time } 4 \\
M(S D) / \%\end{array}$ & $\begin{array}{l}\text { Time } 5 \\
M(S D) / \%\end{array}$ & $\begin{array}{l}\text { Time } 6 \\
M(S D) / \%\end{array}$ & $\begin{array}{l}\text { Time } 7 \\
M(S D) / \%\end{array}$ & $\begin{array}{l}\text { Time } 8 \\
M(S D) / \%\end{array}$ & $\begin{array}{l}\text { Time } 9 \\
M(S D) / \%\end{array}$ \\
\hline Gun carrying & $4.40 \%$ & $5.40 \%$ & $5.30 \%$ & $3.80 \%$ & $5.10 \%$ & $4.30 \%$ & $5.50 \%$ & $6.70 \%$ & $7.90 \%$ \\
\hline \multicolumn{10}{|c|}{ Psychosocial maturity predictors } \\
\hline Impulse control & $3.25(0.86)$ & $3.35(0.86)$ & $3.31(0.89)$ & $3.34(0.89)$ & $3.39(0.87)$ & $3.38(0.86)$ & $3.38(0.87)$ & $3.37(0.87)$ & $3.44(0.86)$ \\
\hline Future orientation & $2.54(0.52)$ & $2.60(0.53)$ & $2.67(0.53)$ & $2.72(0.53)$ & $2.79(0.56)$ & $2.83(0.55)$ & $2.87(0.54)$ & $2.92(0.55)$ & $2.98(0.54)$ \\
\hline \multicolumn{10}{|l|}{ Behavioral predictors } \\
\hline $\begin{array}{l}\text { Non-gun theft and } \\
\text { property offending }\end{array}$ & $37.99 \%$ & $27.03 \%$ & $21.28 \%$ & $18.22 \%$ & $15.74 \%$ & $15.09 \%$ & $13.41 \%$ & $12.84 \%$ & $13.31 \%$ \\
\hline $\begin{array}{l}\text { Non-gun aggressive and } \\
\text { violent offending }\end{array}$ & $43.59 \%$ & $40.93 \%$ & $32.19 \%$ & $28.30 \%$ & $22.14 \%$ & $19.96 \%$ & $16.14 \%$ & $19.46 \%$ & $20.02 \%$ \\
\hline Drug dealing & $14.72 \%$ & $12.7 \%$ & $13.58 \%$ & $10.89 \%$ & $12.05 \%$ & $11.59 \%$ & $10.98 \%$ & $11.69 \%$ & $14.52 \%$ \\
\hline \multicolumn{10}{|l|}{ Social influence predictors } \\
\hline Peer gun carrying & $1.26(0.69)$ & $1.32(0.81)$ & $1.30(0.76)$ & $1.31(0.77)$ & $1.31(0.77)$ & $1.31(0.77)$ & $1.32(0.80)$ & $1.36(0.84)$ & $1.42(0.85)$ \\
\hline $\begin{array}{l}\text { Peer general (non-gun) } \\
\text { offending }\end{array}$ & $1.71(0.67)$ & $1.59(0.66)$ & $1.55(0.69)$ & $1.48(0.63)$ & $1.42(0.60)$ & $1.39(0.59)$ & $1.36(0.57)$ & $1.37(0.57)$ & $1.36(0.55)$ \\
\hline Parent gun carrying & $4.13 \%$ & $3.74 \%$ & $2.86 \%$ & $2.87 \%$ & $3.25 \%$ & $2.10 \%$ & $3.40 \%$ & $2.98 \%$ & $3.36 \%$ \\
\hline $\begin{array}{l}\text { Parent general (non-gun) } \\
\text { offending }\end{array}$ & $17.71 \%$ & $10.86 \%$ & $10.28 \%$ & $7.80 \%$ & $8.04 \%$ & $6.20 \%$ & $5.57 \%$ & $7.65 \%$ & $6.62 \%$ \\
\hline \multicolumn{10}{|l|}{ Victimization predictors } \\
\hline Exposure to gun violence & $11.68 \%$ & $12.89 \%$ & $10.78 \%$ & $9.83 \%$ & $8.15 \%$ & $7.40 \%$ & $8.34 \%$ & $10.92 \%$ & $10.23 \%$ \\
\hline $\begin{array}{l}\text { Exposure to general (non- } \\
\text { gun) violence }\end{array}$ & $41.94 \%$ & $41.75 \%$ & $33.48 \%$ & $27.83 \%$ & $24.89 \%$ & $20.79 \%$ & $21.85 \%$ & $20.23 \%$ & $19.59 \%$ \\
\hline
\end{tabular}

Descriptive statistics are based on observed data (non-imputed). The first 7 interviews (Time 1-Time 7) were conducted in biannual intervals and the last two interviews were conducted annually (Time 8 and Time 9). Mean ages (and SD) at each time-point were: 15.8 (1.3) years at Time 1; $16.3(1.3)$ at Time $2 ; 16.8(1.3)$ years at Time $3 ; 17.3(1.3)$ years at Time 4; $17.8(1.3)$ years at Time $5 ; 18.3(1.3)$ years at Time 6; $18.8(1.3)$ years at Time $7 ; 19.8(1.3)$ years at Time $8 ; 20.8(1.3)$ years at Time 9

Fig. 1 Descriptive statistics for offending and antisocial behavior by time

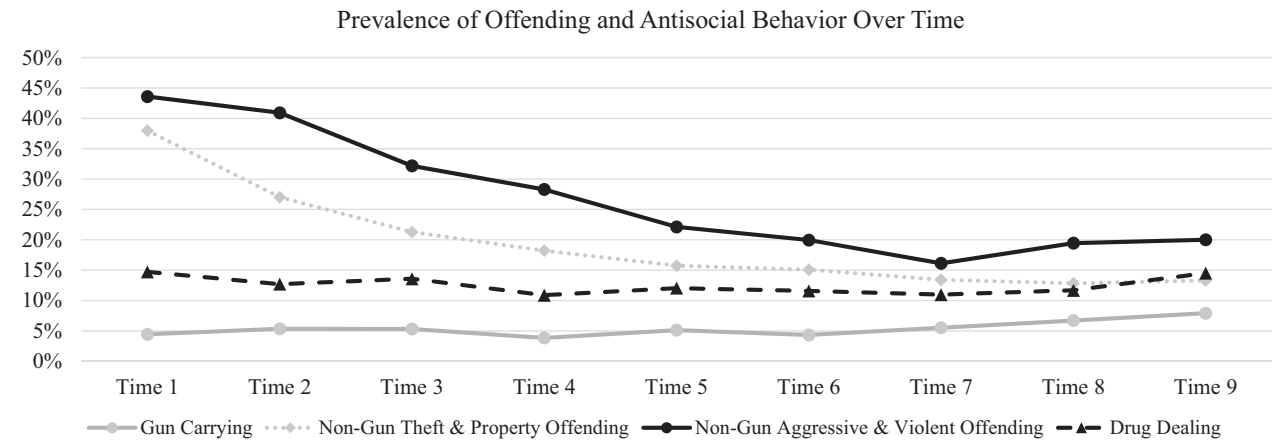

Prevalence of Offending and Antisocial Behavior Over Time

$(p=0.006)$, among those who had carried a gun prior to baseline $(p=0.002)$, and among boys who had peers who carried guns $(p=0.007)$. However, having missing data was not associated with parent highest education $(p=$ $0.544)$, age at time $1(p=0.070)$, impulse control $(p=$ $0.385)$, future orientation $(p=0.708)$, non-gun theft \& property offending $(p=0.445)$, non-gun aggressive \& violent offending $(p=0.355)$, drug dealing $(p=0.231)$, peer non-gun delinquency $(p=0.065)$, parent gun carrying $(p=0.879)$, parent non-gun delinquency $(p=0.161)$, gun victimization $(p=0.139)$, and non-gun victimization $(p=$
0.156). Thus, it is unlikely that missing data had a substantive impact on the results produced from the analyses conducted in the present study. Furthermore, experts in this area have noted that missing data due to participant attrition is less problematic in within-individual models than between-individual models (Hill et al. 2017). Nonetheless, in order to prevent cases with missing data on the predictor variables from being dropped from the analysis, 25 data sets were imputed, and analyses were conducted with the imputed datasets. All results were combined using Rubin's rules (Rubin, 1987). 


\section{Results}

\section{Descriptive Statistics for Gun-Related Study Variables}

As demonstrated in Table 1 and Fig. 1, the prevalence of gun carrying gradually increased throughout the study period. Descriptive univariate growth curve models demonstrated that a quadratic model was a better fit to the data than a linear only model $\left(\mathrm{X}^{2}\right.$ for difference testing $=$ $15.41, p=0.004)$. In the quadratic growth model, the mean and variance were significantly different from zero for the linear slope $($ mean $=0.83 ; p=0.050$; variance $=0.58, p=$ 0.022 ) and the mean was significantly different than zero for the quadratic slope $($ mean $=-0.41, p=0.018$; variance $=$ $0.07, p=0.199)$. Taken together, these growth factors suggest that the overall prevalence of gun carrying gradually increased throughout the study period (with diminished growth towards the end of the study period), and that individuals varied in their rate of change in gun carrying over time. See Table 1, Table 2, and Fig. 1 for more descriptive information about the study variables.

\section{Predictors of Gun Carrying}

When the risk factors from all domains (psychosocial maturity, antisocial behavior, social influence, victimization) were included in the same model (see Table 3, Model 5), the risk factors significantly related to gun carrying were prior gun carrying $(O R=3.92, p=0.031)$, non-gun theft and property offending $(O R=2.08, p<0.001)$, non-gun aggression and violence $(O R=2.15, p=0.004)$, peer gun carrying $(O R=2.13, p<0.001)$, and exposure to gun violence $(O R=$ $4.25, p<0.001)$. As such, young men were significantly more likely to carry guns in years when they engaged in other types of offending (e.g., non-gun theft/property or non-gun aggression/violence) and when they were exposed to guns and gun-related violence (e.g., peer gun carrying, exposure to gun violence)—even after controlling for prior gun carrying and several time-varying confounding factors (see Fig. 2). Interestingly, the coefficients for drug dealing and parent gun carrying were also nearly significant $(O R=1.51, p=0.055$; $O R=1.82, p=0.060$, respectively), suggesting that adolescent and young adult men may also carry guns during years when they sell drugs and/or have parents who carry guns. See Table 3 for estimates for all predictors in the fully adjusted model.

\section{Predictors of Gun Carrying by Time/Age}

In the next stage of the analysis, time-related variations in the associations between the risk factors and gun carrying were first examined by comparing the fully adjusted model
Table 2 Descriptive statistics for time-invariant demographic predictors

\begin{tabular}{|c|c|c|}
\hline Study variable & $M(S D)$ & $\%$ \\
\hline \multicolumn{3}{|l|}{ Race \& Ethnicity } \\
\hline White & & $14.8 \%$ \\
\hline Black & & $36.9 \%$ \\
\hline Hispanic & & $45.8 \%$ \\
\hline Other & & $2.5 \%$ \\
\hline Parent highest education (continuous) & $5.33(2.14)$ & \\
\hline \multicolumn{3}{|l|}{ Parent highest education } \\
\hline Some grade school & & $3.5 \%$ \\
\hline Finished grade school & & $3.9 \%$ \\
\hline Some high school & & $19.6 \%$ \\
\hline GED & & $2.2 \%$ \\
\hline High school diploma & & $32.5 \%$ \\
\hline Business or trade school & & $2.7 \%$ \\
\hline Some college or graduate of 2 year college & & $17.5 \%$ \\
\hline College Graduate of four year college & & $13.4 \%$ \\
\hline $\begin{array}{l}\text { Some graduate or professional school } \\
\text { beyond college }\end{array}$ & & $1.5 \%$ \\
\hline Professional or graduate degree & & $3.3 \%$ \\
\hline IQ proxy & $88.43(11.59)$ & \\
\hline Age (continuous) & $15.80(1.28)$ & \\
\hline \multicolumn{3}{|l|}{ Age } \\
\hline 13 Years Old & & $11.2 \%$ \\
\hline 14 Years Old & & $17.3 \%$ \\
\hline 15 Years Old & & $24.7 \%$ \\
\hline 16 Years Old & & $25.5 \%$ \\
\hline 17 Years Old & & $21.3 \%$ \\
\hline
\end{tabular}

Descriptive statistics are based on observed data (non-imputed)

from the previous step (Table 3, Model 5) to models wherein each risk factor was freely estimated across time. Although four of these model tests were significant based on the $\log$ likelihood $\mathrm{X}^{2}$ tests, a close examination of the estimates revealed that almost none of the fluctuations across time were clinically meaningful (see Supplemental Table 1). The only potentially meaningful fluctuation was in regard to the impact of prior of gun carrying, which may have had a stronger impact on gun carrying in the beginning of the study. An examination of the coefficients in the free models for the other three significant $\mathrm{X}^{2}$ tests suggested that the minor fluctuations by time were likely due to chance (see Supplemental Table 1). In regard to the interactions with age at time 1 , only two of the interactions were significant (i.e., theft and property offending and parent nongun delinquency; see Supplemental Table 2), which suggested that the magnitude of these two risk factors may be stronger for youth who were younger at time 1 (Age $\mathrm{X}$ theft and property offending: $B=-0.26, p=0.023$; Age $\mathrm{X}$ 
Table 3 Associations between the time-varying risk factors and time-invariant demographic factors with gun carrying

\begin{tabular}{|c|c|c|c|c|c|c|c|c|c|c|c|c|c|c|c|}
\hline \multirow[t]{2}{*}{ Predictor } & \multicolumn{3}{|c|}{ Model 1} & \multicolumn{3}{|c|}{ Model 2} & \multicolumn{3}{|c|}{ Model 3} & \multicolumn{3}{|c|}{ Model 4} & \multicolumn{3}{|c|}{ Model 5} \\
\hline & $B$ & $S E$ & $p$ & $B$ & $S E$ & $p$ & $B$ & $S E$ & $p$ & $B$ & $S E$ & $p$ & $B$ & $S E$ & $p$ \\
\hline \multicolumn{16}{|l|}{ Psychosocial Maturity } \\
\hline Impulse control & -0.38 & 0.10 & $<0.001$ & & & & & & & & & & -0.06 & 0.17 & 0.738 \\
\hline Future orientation & -0.24 & 0.15 & 0.107 & & & & & & & & & & -0.23 & 0.22 & 0.295 \\
\hline \multicolumn{16}{|l|}{ Behavioral } \\
\hline Prior gun carrying & & & & 1.04 & 0.20 & $<0.001$ & & & & & & & 1.37 & 0.63 & 0.031 \\
\hline $\begin{array}{l}\text { Non-gun theft \& property } \\
\text { offending }\end{array}$ & & & & 1.24 & 0.17 & $<0.001$ & & & & & & & 0.73 & 0.18 & $<0.001$ \\
\hline $\begin{array}{l}\text { Non-gun aggressive \& violent } \\
\text { offending }\end{array}$ & & & & 1.02 & 0.16 & $<0.001$ & & & & & & & 0.77 & 0.27 & 0.004 \\
\hline Drug dealing & & & & 0.53 & 0.18 & 0.003 & & & & & & & 0.41 & 0.22 & 0.055 \\
\hline \multicolumn{16}{|l|}{ Social influence } \\
\hline Peer gun carrying & & & & & & & 0.78 & 0.09 & $<0.001$ & & & & 0.76 & 0.09 & $<0.001$ \\
\hline Peer general (non-gun) offending & & & & & & & 0.45 & 0.14 & 0.001 & & & & -0.02 & 0.15 & 0.909 \\
\hline Parent gun carrying & & & & & & & 0.56 & 0.30 & 0.063 & & & & 0.60 & 0.32 & 0.060 \\
\hline $\begin{array}{l}\text { Parent general (non-gun) } \\
\text { offending }\end{array}$ & & & & & & & 0.48 & 0.20 & 0.017 & & & & 0.26 & 0.23 & 0.253 \\
\hline \multicolumn{16}{|l|}{ Victimization } \\
\hline Exposure to gun violence & & & & & & & & & & 1.84 & 0.18 & $<0.001$ & 1.45 & 0.19 & $<0.001$ \\
\hline $\begin{array}{l}\text { Exposure to general (non-gun) } \\
\text { violence }\end{array}$ & & & & & & & & & & 0.80 & 0.17 & $<0.001$ & 0.27 & 0.18 & 0.139 \\
\hline \multicolumn{16}{|l|}{ Time-stable demographic factors } \\
\hline \multicolumn{16}{|l|}{ Race \& Ethnicity } \\
\hline Black & & & & & & & & & & & & & 0.26 & 0.35 & 0.461 \\
\hline Hispanic & & & & & & & & & & & & & 0.16 & 0.31 & 0.608 \\
\hline Other & & & & & & & & & & & & & -0.14 & 0.51 & 0.790 \\
\hline Parent highest education & & & & & & & & & & & & & 0.06 & 0.04 & 0.107 \\
\hline IQ proxy & & & & & & & & & & & & & 0.00 & 0.01 & 0.849 \\
\hline Age & & & & & & & & & & & & & 0.09 & 0.08 & 0.260 \\
\hline
\end{tabular}

Notes. All models were estimated with binary fixed-effects logistic regressions in a structural equation framework with maximum likelihood estimation (dynamic panel models). Missing data were imputed with 25 datasets. All models also controlled for time. All predictor variables were concurrent with the outcome except the time-invariant demographic variables (which were measured at baseline) and the lagged dependent variable (lagged interval $=$ Time -1 )

Bold typeface added to emphasize findings that were significant based on $p<0.05$. Italic text added to emphasize findings that were nearly significant $(p<0.065)$

Fig. 2 Within-individual associations between the risk factors and gun carrying. Only risk factors that were significantly related to gun carrying are shown in the figure. ${ }^{*} p<0.05, * * p<0.01, * * * p<$ 0.00

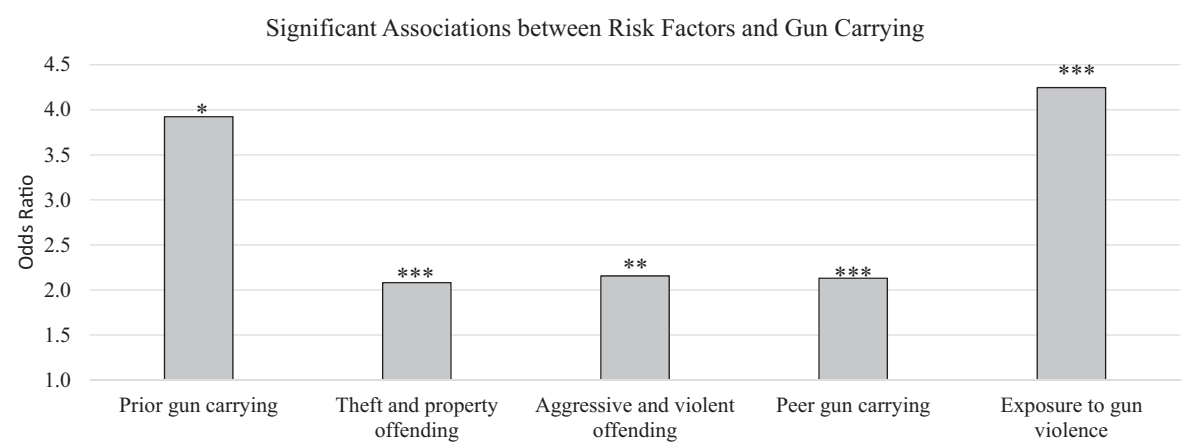


Table 4 Associations between time-varying risk factors and time-invariant demographic factors with non-gun theft and property offending, nongun violence and aggressive offending, and drug dealing

\begin{tabular}{|c|c|c|c|c|c|c|c|c|c|}
\hline \multirow[t]{2}{*}{ Predictor } & \multicolumn{3}{|c|}{$\begin{array}{l}\text { Model 1: Predicting non-gun } \\
\text { theft and property offending }\end{array}$} & \multicolumn{3}{|c|}{$\begin{array}{l}\text { Model 2: Predicting non-gun } \\
\text { aggression and violence }\end{array}$} & \multicolumn{3}{|c|}{$\begin{array}{l}\text { Model 3: Predicting drug } \\
\text { dealing }\end{array}$} \\
\hline & $B$ & $S E$ & $p$ & $B$ & $S E$ & $p$ & $B$ & $S E$ & $p$ \\
\hline \multicolumn{10}{|l|}{ Psychosocial maturity } \\
\hline Impulse control & $-\mathbf{0 . 3 1}$ & $\mathbf{0 . 0 7}$ & $<0.001$ & $-\mathbf{0 . 1 2}$ & 0.06 & 0.050 & 0.04 & 0.05 & 0.394 \\
\hline Future orientation & -0.44 & 0.11 & $<0.001$ & -0.24 & 0.09 & 0.010 & -0.03 & 0.08 & 0.742 \\
\hline \multicolumn{10}{|l|}{ Behavioral } \\
\hline Prior dependent variable & 0.56 & 0.08 & $<0.001$ & 0.32 & 0.08 & $<0.001$ & 0.39 & 0.10 & $<0.001$ \\
\hline Theft and property offending & & & & 0.71 & 0.10 & $<0.001$ & 0.22 & 0.12 & 0.061 \\
\hline $\begin{array}{l}\text { Non-gun related aggression and } \\
\text { violence }\end{array}$ & 0.73 & 0.11 & $<0.001$ & & & & -0.01 & 0.11 & 0.903 \\
\hline Gun carrying & 0.83 & 0.18 & $<0.001$ & 0.58 & 0.17 & 0.001 & 0.32 & 0.19 & 0.094 \\
\hline Drug dealing & 0.16 & 0.12 & 0.185 & 0.09 & 0.11 & 0.388 & & & \\
\hline \multicolumn{10}{|l|}{ Social influence } \\
\hline Peer gun carrying & -0.11 & 0.07 & 0.089 & $-\mathbf{0 . 1 7}$ & 0.06 & 0.005 & -0.07 & 0.07 & 0.300 \\
\hline Peer general (non-gun) offending & 1.13 & 0.10 & $<0.001$ & 1.10 & 0.09 & $<0.001$ & 0.17 & 0.09 & 0.051 \\
\hline Parent gun carrying & 0.19 & 0.25 & 0.450 & -0.13 & 0.23 & 0.579 & -0.04 & 0.26 & 0.865 \\
\hline Parent general (non-gun) offending & 0.50 & 0.14 & $<0.001$ & 0.41 & 0.12 & 0.001 & 0.12 & 0.14 & 0.396 \\
\hline \multicolumn{10}{|l|}{ Victimization } \\
\hline Exposure to gun violence & 0.61 & 0.14 & $<0.001$ & 0.19 & 0.13 & 0.135 & -0.11 & 0.15 & 0.467 \\
\hline $\begin{array}{l}\text { Exposure to general (non-gun) } \\
\text { violence }\end{array}$ & 0.40 & 0.10 & $<0.001$ & 0.76 & 0.09 & $<0.001$ & 0.09 & 0.10 & 0.345 \\
\hline \multicolumn{10}{|l|}{ Time-stable demographic factors } \\
\hline \multicolumn{10}{|l|}{ Race \& Ethnicity } \\
\hline Black & 0.00 & 0.17 & 0.999 & 0.05 & 0.14 & 0.709 & -0.20 & 0.12 & 0.081 \\
\hline Hispanic & 0.18 & 0.16 & 0.259 & 0.05 & 0.14 & 0.708 & 0.10 & 0.11 & 0.389 \\
\hline Other & -0.34 & 0.35 & 0.327 & 0.23 & 0.28 & 0.415 & -0.33 & 0.26 & 0.208 \\
\hline Parent highest education & 0.01 & 0.03 & 0.857 & 0.01 & 0.02 & 0.697 & 0.00 & 0.02 & 0.982 \\
\hline IQ proxy & 0.00 & 0.01 & 0.799 & 0.00 & 0.00 & 0.694 & 0.01 & 0.00 & 0.053 \\
\hline Age & 0.06 & 0.04 & 0.166 & -0.25 & 0.04 & 0.000 & -0.01 & 0.03 & 0.775 \\
\hline
\end{tabular}

Notes. All models were estimated with binary fixed-effects logistic regressions in a structural equation framework with maximum likelihood estimation (dynamic panel models). Missing data were imputed with 25 datasets. All models also controlled for time. All predictor variables were concurrent with the outcome except the time-invariant demographic variables (which were measured at baseline) and the lagged dependent variable (lagged interval $=$ Time -1$)$. Note that Time 1 was not included in the model estimating drug dealing because of convergence problems in the imputation model

Bold typeface added to table to emphasize findings that were significant based on $p<0.05$

parent non-gun: $B=-0.43, p=0.005)$. Nonetheless, all things considered, the analyses in the present study did not produce consistent and compelling evidence that the nature of the risk factors for gun carrying substantially changed during adolescence and the transition to young adulthood.

\section{Supplemental Analyses}

The next step of the analysis examined whether the predictors of gun carrying were similar to the predictors of other types of offending. The within-individual associations between the risk factors and non-gun theft and property offending, non-gun aggression and violence, and drug dealing are shown in Table 4. As shown in the table, the predictors of non-gun offending were different than the predictors of gun carrying. For example, young men were significantly more likely to engage in theft and property offending and aggression and violence during years when they experienced significant declines in impulse control and future orientation and when they experienced significant increases in peer non-gun offending, parent non-gun offending, and exposure to non-gun violence. None of these risk factors (i.e., impulse control; future orientation; non-gun peer offending; non-gun parent offending; 
exposure to non-gun violence) were significantly related to gun carrying in the fully adjusted model. Interestingly, the only risk factor significantly related to drug dealing was prior drug dealing (see Table 4, Model 3).

\section{Sensitivity Analyses}

In the final stage of the analysis, two sensitivity models were examined. The first issue examined was the decision to dichotomize three of the variables in the primary model. The second issue examined was the decision to impute 25 datasets. The results from these models are shown in Supplemental Table 3 and Supplemental Table 4. As shown in the tables, results are very similar to the primary models.

\section{Discussion}

Although prior studies have identified many important risk factors for gun carrying, the existing body of work suffers from several limitations. Most importantly, no prior study has simultaneously examined four potential explanations for gun carrying together in a single dynamic within-individual change model, particularly while controlling for youths' prior propensity to carry a gun. Furthermore, no studies examined whether the salience of various risk factors for gun carrying changes across adolescence and the transition to adulthood. Indeed, there are many socio-emotional and contextual differences between adolescents and young adults, and these differences may impact the degree to which risk factors are related to gun carrying. The present study was designed to overcome the shortcomings in prior work by examining the extent to which several psychological, behavioral, and contextual explanatory factors were related to gun carrying during adolescence and early young adulthood, and by examining whether any of the associations changed with age. In general, the strongest withinperson predictors of gun carrying were engaging in other antisocial and illegal behavior and exposure to gun-related events (e.g., peer gun carrying, exposure to gun violence).

\section{Behavioral}

The present study found that the more robust predictors of gun carrying were engaging in theft and property offending, engaging in aggression and violence, and to a lesser extent, engaging in drug dealing, consistent with prior work. This finding suggests that young men were more likely to carry guns during periods when they engaged in other types of antisocial and illegal behavior. It is possible that guns are used as tools to facilitate other antisocial goals or for protection while engaging in other illegal activities. It was interesting that the only risk factors related to gun carrying after controlling for co-occurring antisocial behavior and prior gun carrying were exposure to gun-related events such as peer gun carrying and exposure to gun violence in their communities.

\section{Social Influence}

Consistent with socialization and social contagion processes (Tracy et al., 2016), the present study found that youth were more likely to carry guns in years when their peers (and to some extent their parents) carried a gun. It is possible that peers (and possibly parents) promoted youth gun carrying through direct encouragement and indirect modeling, or by normalizing and glorifying guns. It is also possible that these factors were correlated with youth gun carrying because they all signal that the individual was exposed to a social culture in which guns were easily accessible, or because associating with antisocial peers provided access to guns and/or illegal gun markets. An additional potential explanation is that youth who carried guns sought out peer groups where guns were used (i.e., selection). The precise mechanisms linking these factors to gun carrying (and the direction of the effects) were not directly examined in the present study, although the present study did statistically control for youths' prior propensity to carry a gun, suggesting a greater likelihood of socialization rather than selection. Nonetheless, it was striking that having peers who carried guns was significantly related to youth gun carrying, even after controlling for prior carrying, youths' own cooccurring antisocial and illegal behavior, psychosocial deficits, victimization, and time-stable demographic factors.

\section{Victimization}

In addition to potentially being socialized by peers (and maybe parents), the results suggest that youth may carry guns for self-protection or retaliation. This is consistent with prior studies showing that victims of violence are significantly more likely than others to carry guns and other weapons (Molnar et al., 2004; Reid et al., 2017; Spano, 2012; Spano \& Bolland, 2013; Spano \& Bolland, 2011; Van Geel et al., 2014; Vaughn et al., 2006; Vaughn et al., 2012; Wallace, 2017). Interestingly, it was found that youth were more likely to carry guns in years when they were exposed to gun violence but not when they were exposed to non-gun-related violence, similar to prior work with serious adolescent offenders (Beardslee et al., 2018). For example, the odds of carrying a gun in the present study were about 4.3 times higher during years when a youth was the victim or witness of gun violence compared to other years, but gun carrying was not significantly elevated during years when the youth was exposed to serious violence that was not accompanied by guns (i.e., beaten up). 
These findings highlight the unique and specific association between gun victimization and gun carrying and suggest that youth gun carrying is most likely to occur during years when the youth witnesses someone getting shot - whether they are the victim or not. It is possible that youth carry guns to protect themselves and others from future gunrelated attacks or to retaliate against attackers. Indeed, it is possible that youth chose a weapon of similar lethality when trying to prevent future attacks or retaliating. Importantly, the impact of exposure to gun violence was significant even after controlling for the participant's own prior gun carrying, theft and property offending, and aggressive and violent offending. The present study did not examine whether gun carrying "worked" in terms of preventing future gun attacks, although prior studies suggest that gun and other weapon carrying actually leads to more, not less, violence (Carter et al., 2013; Pickett et al., 2005; Watts, 2019). For example, one study found that the odds of experiencing gun victimization were almost 2.5 times higher for youth who carried a gun in the prior time-point, even after controlling for a comprehensive set of covariates (Watts, 2019).

\section{Age Interactions}

In general, the analysis in the present study found that the nature of the risk factors for gun carrying largely did not change with age. The only potential exceptions to this were in regard to prior gun carrying and theft and property offending, which may be stronger predictors of gun carrying at younger ages. These results suggests that gun carrying may have more risk factors in adolescence and that gun carrying may be more sporadic or episodic in early young adulthood than in adolescence. However, it is important to consider that the vast majority of the age analyses were not significant, suggesting that the predictors of gun carrying generally did not change across adolescence and the transition to adulthood.

\section{Correspondence Between Predictors of Gun Carrying and Other Antisocial/Illegal Behaviors}

An additional question examined in the present study was whether the risk factors for gun carrying were different than the risk factors for other non-gun offending. From a practical standpoint, it is important to examine the unique predictors of gun carrying to determine the extent to which established intervention and prevention programs for other conduct problems should be tailored to specifically address gun carrying or whether they could be applied broadly. The analysis in the present study found that the factors significantly related to gun carrying were mostly circumscribed to the gun-related risk factors and co-occurring other offending, while a variety of risk factors were related to the non-gun offending outcomes. For example, future orientation, impulse control, peer general (non-gun) offending, parent general (non-gun) offending, and exposure to non-gun violence were all significantly related to theft and property offending and violent and aggressive offending, while none of these factors were significantly associated with gun carrying. As such, the findings in the present study suggest that the unique risk factors for youth gun carrying should be taken into consideration when designing and implementing gun violence prevention and intervention programs. One of the key goals of programs designed to reduce gun carrying should be to reduce young men's real, implied, and perceived exposure to gun-related events in their social networks and communities.

\section{Limitations}

The results from the present study should be considered in light of the study limitations. For example, the authors examined the research questions with data from a sample of male youth who were recruited into the study after their first contact with the juvenile justice system. As such, results may not generalize to other demographic groups (e.g., clinical, women, community samples). However, it was interesting that many of the observed associations in the present study were consistent with prior published work conducted with a slightly older study of serious adolescent offenders. Nonetheless, future research should examine the research questions with other samples. In addition, the mechanisms linking the significant risk factors to gun carrying were not directly measured, although it was hypothesized that peer gun carrying was significantly related to youth gun carrying because friends modeled, encouraged, or normalized gun carrying (consistent with socialization processes) and that exposure to gun violence was significantly related to gun carrying because youth who were the victims of gun violence were motivated to protect themselves or retaliate. However, it could be that all of these risk factors correlated with youth gun carrying because these are all symptoms of an environment where firearms are ubiquitous and accessible. It is important for future work to examine whether firearm access impacts the associations observed in the present study. Prior studies show that youth who perceive easier access to guns are more likely to carry and use guns than other youth (Gonzales \& McNiel, 2020; Hemenway et al., 2011; Keil et al., 2020; Lizotte et al., 2000; Molnar et al., 2004), but none of these studies examined whether perceived gun access is associated with youth gun use in within-individual change models. Unfortunately, perceived gun access was not measured in the present study. In addition, our measures of peer and parent gun carrying and other offending were based on youths' perceptions of peer and parent behavior and may not perfectly represent their true behavior. One study suggests that 
youth may overestimate the prevalence of peer gun carrying (Hemenway et al., 2011). Future work should consider including reports directly from peers and parents to determine the extent to which youths' perceptions match reality. Moreover, our measure of gun violence exposure-being shot or witnessing someone being shot-was a relatively severe measure of gun violence and thus it is unclear whether being threatened or witnessing someone threatened with a gun, but not shot, would be similarly related to youth gun carrying. Furthermore, it is possible that interactions among the risk factors were significantly related to gun carrying. Consistent with this idea, one prior study found that the impact of peer gun carrying was stronger for youth with low callous and unemotional traits (Robertson et al., 2020). Although the present study was not able to include all possible interactions, this is an area for future research. Additionally, the measure of gun carrying did not distinguish between legal and illegal gun carrying. While gun carrying is illegal for minors, some states allow adults to own and carry guns in some capacity. Two of the sites in the present study, Pennsylvania (https://www.psp.pa.gov/firea rms-information/Pages/Carrying-Firearms-in-Pennsylvania. aspx) and Louisiana (https://gunlawsuits.org/gun-laws/ Louisiana/open-carry/), tend to have more permissive gun laws, while the third site, California, has some of the strictest gun laws in the country (https://oag.ca.gov/sites/all/ files/agweb/pdfs/firearms/pdf/cfl2016.pdf; https://oag.ca. gov/firearms/pubfaqs\#1). Finally, it is important to keep in mind that almost all of the risk factors and the outcome, gun carrying, were measured at the same time-period. It is hypothesized that the direction of the effect was from the risk factors to gun carrying, but the precise temporal ordering was not tested in the present study.

\section{Conclusion}

Prior studies have identified a handful of potential explanations for gun carrying during adolescence and early young adulthood. For example, studies have suggested that adolescents and young adult are more likely to carry guns if their peers carry guns, if they have been exposed to violence, and if they have low psychosocial maturity. However, no prior study has simultaneously examined several potential risk factors in a dynamic within-individual change model, controlled for youth's prior gun carrying and other co-occurring offending, included a variety of gun and nongun related sources of social influence, included both peer and parent factors, and examined whether the magnitude of the predictors change with age. The present study found that the factors with the strongest associations with gun carrying during adolescence and the transition to young adulthood were largely circumscribed to other gun-related events, including peer gun carrying and exposure to gun violence, and co-occurring offending, including theft and property offending and aggressive and violent offending. Similar to communicable diseases, the results support the idea that a gun-related event may produce a ripple or contagion effect (see Green et al., 2017; Towers et al., 2015), which demonstrates that efforts to reduce gun violence should work to prevent the transmission of gun carrying from one person to another within a social network. Physicians, parents, and educators who learn about a young person's exposure to a gun-related event should screen and refer youth to targeted prevention and intervention programs to prevent future gun carrying among those exposed. Based on the results in the present study, gun violence intervention and prevention programs should be tailored to specifically emphasize the reduction of adolescents' and young adults' real and perceived exposure to gun-related events in their communities, in addition to reducing overall levels of criminal recidivism among justice-system involved youth.

Acknowledgements We are grateful to the study participant and their families, the research assistants who worked on this project, the project coordinators in the three sites, and the many other individuals who made this study possible.

Authors' Contributions J.B. conducted the analyses and contributed to the study design, interpretation of study results, and manuscript preparation; D.P. assisted with the analytic plan, the study design, interpretation of results, and manuscript preparation; E.K., C.S. and M.P. assisted with the study design, interpretation of results, and manuscript preparation; P.J.F. and L.S. assisted with the study design, interpretation of results, and manuscript preparation, and co-led data collection for the Crossroads study; E.C. assisted with the study design, interpretation of results, and manuscript preparation, and is the Principal Investigator on the Crossroads study. All authors read and approved the final manuscript.

Funding The Crossroads Study is supported by funding from the John D. and Catherine T. MacArthur Foundation, the Office of Juvenile Justice and Delinquency Prevention, the Fudge Family Foundation, the William T. Grant Foundation, the County of Orange, and the National Institute of Justice.

Data Sharing Declaration De-identified data will be archived and available for use when data collection for the Crossroads study is completed.

\section{Compliance with Ethical Standards}

Conflict of Interest The authors declare no competing interests.

Research Involving Human Participants and/or Animals All study procedures were approved by the Institutional Review Boards at the Participating Universities.

Informed Consent Informed parental consent and youth assent were obtained for all participants in the study. 
Publisher's note Springer Nature remains neutral with regard to jurisdictional claims in published maps and institutional affiliations.

Open Access This article is licensed under a Creative Commons Attribution 4.0 International License, which permits use, sharing, adaptation, distribution and reproduction in any medium or format, as long as you give appropriate credit to the original author(s) and the source, provide a link to the Creative Commons license, and indicate if changes were made. The images or other third party material in this article are included in the article's Creative Commons license, unless indicated otherwise in a credit line to the material. If material is not included in the article's Creative Commons license and your intended use is not permitted by statutory regulation or exceeds the permitted use, you will need to obtain permission directly from the copyright holder. To view a copy of this license, visit http://creativecommons. org/licenses/by/4.0/.

\section{References}

Allison, P. (2009). Fixed effects regression models. Sage Publications. Barnes, G. M., Hoffman, J. H., Welte, J. W., Farrell, M. P., \& Dintcheff, B. A. (2006). Effects of parental monitoring and peer deviance on substance use and delinquency. Journal of Marriage and Family, 68, 1084-1104. https://doi.org/10.1111/j.1741-3737. 2006.00315.x.

Beardslee, J., Docherty, M., Mulvey, E., \& Pardini, D. (2021). The direct and indirect associations between childhood socioeconomic disadvantage and adolescent gun violence. Journal of Clinical Child and Adolescent Psychology, 1-11. https://doi.org/10.1080/ 15374416.2019.1644646.

Beardslee, J., Docherty, M., Yang, V., \& Pardini, D. (2019). Parental disengagement in childhood and adolescent gun carrying. Pediatrics, 143, 1-9. https://doi.org/10.1542/peds.2018-1552.

Beardslee, J., Mulvey, E. P., Schubert, C., Allison, P., Infante, A., \& Pardini, D. (2018). Gun and non-gun related violence exposure and risk for subsequent gun carrying among male juvenile offenders. Journal of the American Academy of Child and Adolescent Psychiatry, 57, 274-279. https://doi.org/10.1016/j.jaac. 2018.01.012.

Bechtold, J., Cavanagh, C., Shulman, E. P., \& Cauffman, E. (2014). Does mother know best? Adolescent and mother reports of impulsivity and subsequent delinquency. Journal of Youth and Adolescence, 43, 1903-1913. https://doi.org/10.1007/s10964013-0080-9.

Bollen, K. A., \& Brand, J. E. (2010). A general panel model with random and fixed effects: a structural equations approach. Social Forces, 89(1), 1-34. https://doi.org/10.1353/sof.2010.0072.

Branas, C. C., Richmond, T. S., Culhane, D. P., Ten Have, T. R., \& Wiebe, D. J. (2009). Investigating the link between gun possession and gun assault. American Journal of Public Health, 99, 2034-2040. https://doi.org/10.2105/AJPH.2008.143099.

Cao, L., Zhang, Y., \& He, N. (2008). Carrying weapons to school for protection: an analysis of the 2001 school crime supplement data. Journal of Criminal Justice, 36, 154-164. https://doi.org/10. 1016/j.jcrimjus.2008.02.005.

Carter, P. M., Walton, M. A., Newton, M. F., Clery, M., Whiteside, L. K., Zimmerman, M. A., \& Cunningham, R. M. (2013). Firearm possession among adolescents presenting to an urban emergency department for assault. Pediatrics, 132, 213-221. https://doi.org/ 10.1542/peds.2013-0163.

Cauffman, E., Beardslee, J., Fine, A., Frick, P. J., \& Steinberg, L. (2021). Crossroads in juvenile justice: the impact of initial processing decision on youth 5 years after first arrest. Development and psychopathology, 33(2), 700-713. https://doi.org/10.1017/ S095457942000200X.
Centers for Disease Control (2012). Youth risk behavior surveillanceUnited States, 2011. Morbidity and Mortality Weekly Report, 61 (4), 1-45. https://www.cdc.gov/mmwr/pdf/ss/ss6104.pdf

Centers for Disease Control (2021a). Firearm Violence Prevention. https://www.cdc.gov/violenceprevention/firearms/fastfact.html

Centers for Disease Control (2021b). WISQARS-Web-based Injury Statistics Query and Reporting System. https://www.cdc.gov/ injury/wisqars/index.html

Decker, S. H., Pennell, S., \& Caldwell, A. (1997). Illegal firearms: access and use by arrestees. National Institute of Justice Research in Brief.

Docherty, M., Beardslee, J., Grimm, K. J., \& Pardini, D. (2019a). Distinguishing between-individual from within-individual predictors of gun carrying among Black and White males across adolescence. Law and Human Behavior, 43, 144-155. https://doi. org/10.1037/lhb0000320.

Docherty, M., Mulvey, E., Beardslee, J., Sweeten, G., \& Pardini, D. (2019b). Drug dealing and gun carrying go hand in hand: Examining how juvenile offenders' gun carrying changes before and after drug dealing spells across 84 months. Journal of Quantitative Criminology, 1-23. https://doi.org/10.1007/s10940019-09442-9.

Dong, B., \& Wiebe, D. J. (2018). Violence and beyond: Life-course features of handgun carrying in the urban United States and the associated long-term life consequences. Journal of criminal justice, 54, 1-11. https://doi.org/10.1016/j.jcrimjus.2017.11.002.

Fergusson, D. M., Swain-Campbell, N. R., \& Horwood, L. J. (2002). Deviant peer affiliations, crime and substance use: a fixed effects regression analysis. Journal of Abnormal Child Psychology, 30, 419-430. https://doi.org/10.1023/A:1015774125952.

Fine, A., Steinberg, L., Frick, P. J., \& Cauffman, E. (2016). Selfcontrol assessments and implications for predicting adolescent offending. Journal of Youth and Adolescence, 45, 701-712. https://doi.org/10.1007/s10964-016-0425-2.

Gonzales, L., \& McNiel, D. E. (2020). Correlates of gun violence by criminal justice-involved adolescents. Law and Human Behavior, 44, 238-249. https://doi.org/10.1037/lhb0000349.

Green, B., Horel, T., \& Papachristos, A. V. (2017). Modeling contagion through social networks to explain and predict gunshot violence in Chicago, 2006 to 2014. JAMA Internal Medicine, 177, 326-333. https://doi.org/10.1001/jamainternmed.2016.8245.

Greenberger, E., \& Sørensen, A. B. (1974). Toward a concept of psychosocial maturity. Journal of Youth and Adolescence, 3, 329-358. https://doi.org/10.1007/BF02214746.

Guo, J., Chung, I.-J., Hill, K. G., Hawkins, J. D., Catalano, R. F., \& Abbott, R. D. (2002). Developmental relationships between adolescent substance use and risky sexual behavior in young adulthood. Journal of Adolescent Health, 31, 354-362. https:// doi.org/10.1016/S1054-139X(02)00402-0.

Hemenway, D., Vriniotis, M., Johnson, R. M., Miller, M., \& Azrael, D. (2011). Gun carrying by high school students in Boston, MA: does overestimation of peer gun carrying matter? Journal of Adolescence, 34, 997-1003. https://doi.org/10.1016/j. adolescence.2010.11.008.

Hill, J. M., van der Geest, V. R., \& Blokland, A. J. (2017). Leaving the bank of mum and dad: financial independence and delinquency desistance in emerging adulthood. Journal of Developmental and Life-Course Criminology, 3, 419-439. https://doi.org/10.1007/ s40865-017-0058-5.

Huizinga, D., Esbensen, F. A., \& Weiher, A. W. (1991). Are there multiple paths to delinquency? Journal of Criminal Law, Criminology and Police Science, 82, 83-118.

Johnson, W. L., Giordano, P. C., Manning, W. D., \& Longmore, M. A. (2011). Parent-child relations and offending during young adulthood. Journal of Youth and Adolescence, 40, 786-799. https://doi.org/10.1007/s10964-010-9591-9. 
Keil, S., Beardslee, J., Schubert, C., Mulvey, E., \& Pardini, D. (2020). Perceived gun access and gun carrying among male adolescent offenders. Youth Violence and Juvenile Justice, 18, 179-195. https://doi.org/10.1177/1541204019865312.

Kleck, G., \& Gertz, M. (1998). Carrying guns for protection: results from the national self-defense survey. Journal of Research in Crime \& Delinquency, 35, 193-224. https://doi.org/10.1177/ 0022427898035002004.

Lee, D. B., Hsieh, H. F., Stoddard, S. A., Heinze, J. E., Carter, P. M., Goldstick, J. E., Cunningham, M. C., Cunningham, R. M., \& Zimmerman, M. A. (2020). Longitudinal pathway from violence exposure to firearm carriage among adolescents: the role of future expectation. Journal of adolescence, 81, 101-113. https://doi.org/ 10.1016/j.adolescence.2020.03.009.

Lizotte, A. J., Krohn, M. D., Howell, J. C., Tobin, K., \& Howard, G. J. (2000). Factors influencing gun carrying among young urban males over the adolescent-young adult life course. Criminology, 38, 811-834. https://doi.org/10.1111/j.1745-9125.2000.tb00907.x.

Loeber, R., Burke, J. D., Mutchka, J., \& Lahey, B. B. (2004). Gun carrying and conduct disorder: a highly combustible combination? Implications for juvenile justice and mental and public health. Archives of Pediatrics and Adolescent Medicine, 158, 138-145. https://doi.org/10.1001/archpedi.158.2.138.

Loughran, T. A., Reid, J. A., Collins, M. E., \& Mulvey, E. P. (2016). Effect of gun carrying on perceptions of risk among adolescent offenders. American Journal of Public Health, 106, 350-352. https://doi.org/10.2105/AJPH.2015.302971.

Molnar, B. E., Miller, M. J., Azrael, D., \& Buka, S. L. (2004). Neighborhood predictors of concealed firearm carrying among children and adolescents: Results from the project on human development in chicago neighborhoods. Archives of Pediatrics \& Adolescent Medicine, 158, 657-664. https://doi.org/10.1001/a rchpedi.158.7.657.

Monahan, K., Steinberg, L., Cauffman, E., \& Mulvey, E. (2013). Psychosocial (im) maturity from adolescence to early adulthood: distinguishing between adolescence-limited and persisting antisocial behavior. Development and Psychopathology, 25, 1093-1105. https://doi.org/10.1017/S0954579413000394.

Monahan, K. C., Steinberg, L., Cauffman, E., \& Mulvey, E. P. (2009). Trajectories of antisocial behavior and psychosocial maturity from adolescence to young adulthood. Developmental Psychology, 45, 1654-1668. https://doi.org/10.1037/a0015862.

Oliphant, S. N., Mouch, C. A., Rowhani-Rahbar, A., Hargarten, S., Jay, J., Hemenway, D., Zimmerman, M., Carter, P. M., \& Consortium, F. (2019). A scoping review of patterns, motives, and risk and protective factors for adolescent firearm carriage. Journal of Behavioral Medicine, 42, 763-810. https://doi.org/10.1007/ s10865-019-00048-x.

Pardini, D., Beardslee, J., Docherty, M., Schubert, C., \& Mulvey, E. (2020). Risk and protective factors for gun violence in male juvenile offenders. Journal of Clinical Child \& Adolescent Psychology, 1-16. https://doi.org/10.1080/15374416.2020.1823848.

Pickett, W., Craig, W., Harel, Y., Cunningham, J., Simpson, K., Molcho, M., Mazur, J., Dostaler, S., Overpeck, M. D., \& Currie, C. E. (2005). Cross-national study of fighting and weapon carrying as determinants of adolescent injury. Pediatrics, 116, e855-e863. https://doi.org/10.1542/peds.2005-0607.

Piquero, A. (2000). Frequency, specialization, and violence in offending careers. Journal of Research in Crime and Delinquency, 37, 392-418. https://doi.org/10.1177/0022427800037004003.

Reid, J. A., Richards, T. N., Loughran, T. A., \& Mulvey, E. P. (2017). The relationships among exposure to violence, psychological distress, and gun carrying among male adolescents found guilty of serious legal offenses: a longitudinal cohort study. Annals of Internal Medicine, 166, 412-418. https://doi.org/10.7326/M161648 .
Robertson, E. L., Frick, P. J., Walker, T. M., Kemp, E. C., Ray, J. V., Thornton, L. C., Wall Myers, T. D., Steinberg, L., \& Cauffman, E. (2020). Callous-Unemotional Traits and Risk of Gun Carrying and Use During Crime. American Journal of Psychiatry, Advanced Online Publication. https://doi.org/10.1176/appi.ajp. 2020.19080861.

Rowan, Z. R., Schubert, C. A., Loughran, T. A., Mulvey, E. P., \& Pardini, D. A. (2019). Proximal predictors of gun violence among adolescent males involved in crime. Law and Human Behavior, 43, 250-262. https://doi.org/10.1037/lhb0000327.

Rubin, D. (1987). Multiple Imputation for Nonresponse in Surveys. New York, NY: John Wiley and sons.

Santilli, A., O'Connor Duffany, K., Carroll-Scott, A., Thomas, J., Greene, A., Arora, A., Agnoli, A., Gan, G., \& Ickovics, J. (2017). Bridging the response to mass shootings and urban violence: exposure to violence in New Haven, Connecticut. American journal of public health, 107(3), 374-379. https://doi.org/10. 2105/AJPH.2016.303613.

Schmidt, C. J., Rupp, L., Pizarro, J. M., Lee, D. B., Branas, C. C., \& Zimmerman, M. A. (2019). Risk and protective factors related to youth firearm violence: a scoping review and directions for future research. Journal of Behavioral Medicine, 42, 706-723. https:// doi.org/10.1007/s10865-019-00076-7.

Selner-O'Hagan, M. B., Kindlon, D. J., Buka, S. L., Raudenbush, S. W., \& Earls, F. J. (1998). Assessing exposure to violence in urban youth. The Journal of Child Psychology and Psychiatry and Allied Disciplines, 39, 215-224. https://doi.org/10.1111/14697610.00315.

Sheley, J. F., \& Wright, J. D. (1993). Motivations for gun possession and carrying among serious juvenile offenders. Behavioral Sciences and the Law, 11, 375-388. https://doi.org/10.1002/bsl. 2370110405.

Shulman, E. P., Beardslee, J., Fine, A., Frick, P. J., Steinberg, L., \& Cauffman, E. (2021). Exposure to gun violence: associations with anxiety, depressive symptoms, and aggression among male juvenile offenders. Journal of Clinical Child \& Adolescent Psychology, 1-14. https://doi.org/10.1080/15374416.2021.1888742.

Simon, L. M. (1997). Do criminal offenders specialize in crime types? Applied and Preventive Psychology, 6, 35-53. https://doi.org/10. 1016/S0962-1849(05)80064-2.

Spano, R. (2012). First time gun carrying and the primary prevention of youth gun violence for African American youth living in extreme poverty. Aggression and Violent Behavior, 17, 83-88. https://doi.org/10.1016/j.avb.2011.10.002.

Spano, R., \& Bolland, J. (2013). Disentangling the effects of violent victimization, violent behavior, and gun carrying for minority inner-city youth living in extreme poverty. Crime \& Delinquency, 59, 191-213. https://doi.org/10.1177/0011128710372196.

Spano, R., \& Bolland, J. M. (2011). Is the nexus of gang membership, exposure to violence, and violent behavior a key determinant of first time gun carrying for urban minority youth? Justice Quarterly, 28, 838-862. https://doi.org/10.1080/07418825.2010. 547868.

Spano, R., Rivera, C., \& Bolland, J. M. (2010). Are chronic exposure to violence and chronic violent behavior closely related developmental processes during adolescence? Criminal Justice and Behavior, 37, 1160-1179. https://doi.org/10.1177/ 0093854810377164.

Steinberg, L., \& Cauffman, E. (1996). Maturity of judgment in adolescence: psychosocial factors in adolescent decision making. Law and Human Behaviors, 20, 249-272. https://doi.org/10. 1007/BF01499023.

Steinman, K. J., \& Zimmerman, M. A. (2003). Episodic and persistent gun-carrying among urban African-American adolescents. Journal of Adolescent Health, 32(5), 356-364. https://doi.org/10. 1016/S1054-139X(03)00022-3. 
Sumner, S. A., Maenner, M. J., Socias, C. M., Mercy, J. A., Silverman, P., Medinilla, S. P., Martin, S. S., Xu, L., \& Hillis, S. D. (2016). Sentinel events preceding youth firearm violence: An investigation of administrative data in Delaware. American Journal of Preventive Medicine, 51, 647-655. https://doi.org/10.1016/j. amepre.2016.08.002.

Teplin, L. A. (2019). Firearm involvement in delinquent youth and collateral consequences in young adulthood: a prospective longitudinal study (Report No. 254133). U.S. Department of Justice.

Thornberry, T. P., Lizotte, A. J., Krohn, M. D., Farnworth, M., \& Jang, S. J. (1994). Delinquent peers, beliefs, and delinquent behavior: a longitudinal test of interactional theory. Criminology, 32, 47-83. https://doi.org/10.1111/j.1745-9125.1994.tb01146.x.

Towers, S., Gomez-Lievano, A., Khan, M., Mubayi, A., \& CastilloChavez, C. (2015). Contagion in mass killings and school shootings. PLoS ONE, 10, 1-12. https://doi.org/10.1371/journal.pone. 0117259.

Tracy, M., Braga, A. A., \& Papachristos, A. V. (2016). The transmission of gun and other weapon-involved violence within social networks. Epidemiologic Reviews, 38(1), 70-86. https://doi.org/ 10.1093/epirev/mxv009.

Van Geel, M., Vedder, P., \& Tanilon, J. (2014). Bullying and weapon carrying: a meta-analysis. JAMA pediatrics, 168, 714-720. https://doi.org/10.1001/jamapediatrics.2014.213.

Van Ryzin, M., Fosco, G., \& Dishion, G. (2012). Family and peer predictors of substance use from early adolescence to early adulthood: an 11-year prospective analysis. Addictive Behaviors, 37, 1314-1324. https://doi.org/10.1016/j.addbeh.2012.06.020.

Vaughn, M. G., Howard, M. O., \& Harper-Chang, L. (2006). Do prior trauma and victimization predict weapon carrying among delinquent youth? Youth Violence and Juvenile Justice, 4, 314-327. https://doi.org/10.1177/1541204006292665.

Vaughn, M. G., Oh, S., Salas-Wright, C. P., DeLisi, M., Holzer, K. J., \& McGuire, D. (2019). Sex differences in the prevalence and correlates of handgun carrying among adolescents in the United States. Youth violence and juvenile justice, 17(1), 24-41. https:// doi.org/10.1177/1541204017739072.

Vaughn, M. G., Perron, B. E., Abdon, A., Olate, R., Groom, R., \& $\mathrm{Wu}$, L.-T. (2012). Correlates of handgun carrying among adolescents in the United States. Journal of Interpersonal Violence, 27, 2003-2021. https://doi.org/10.1177/0886260511432150.

Vaughn, M. G., Nelson, E. J., Salas-Wright, C. P., DeLisi, M., \& Qian, Z. (2016). Handgun carrying among White youth increasing in the United States: new evidence from the National Survey on Drug Use and Health 2002-2013. Preventive medicine, 88, 127-133. https://doi.org/10.1016/j.ypmed.2016.03.024.

Wallace, L. N. (2017). Armed kids, armed adults? Weapon carrying from adolescence to adulthood. Youth Violence and Juvenile Justice, 15, 84-98. https://doi.org/10.1177/1541204015585363.

Watkins, A. M., Huebner, B. M., \& Decker, S. H. (2008). Patterns of gun acquisition, carrying, and use among juvenile and adult arrestees: evidence from a high-crime city. Justice Quarterly, 25, 674-700. https://doi.org/10.1080/07418820801930118.

Watts, S. J. (2019). Gun carrying and gun victimization among American adolescents: a fresh look at a nationally representative sample. Victims \& Offenders, 14(1), 1-14. https://doi.org/10. 1080/15564886.2018.1536005.

Wechsler, D. (1999). Wechsler abbreviated scale of intelligence manual. San Antonio, TX: The Psychological Corporation.

Weinberger, D. A., \& Schwartz, G. E. (1990). Distress and restraint as superordinate dimensions of self-reported adjustment: a typological perspective. Journal of Personality, 58, 381-417. https:// doi.org/10.1111/j.1467-6494.1990.tb00235.x.
Wilkinson, D. L., McBryde, M. S., Williams, B., Bloom, S., \& Bell, K. (2009). Peers and gun use among urban adolescent males: an examination of social embeddedness. Journal of Contemporary Criminal Justice, 25(1), 20-44. https://doi.org/10.1177/ 1043986208328449.

Williams, R., Allison, P. D., \& Moral-Benito, E. (2018). Linear dynamic panel-data estimation using maximum likelihood and structural equation modeling. The Stata Journal, 18(2), 293-326. https://doi.org/10.1177/1536867X1801800201.

Jordan Beardslee is a developmental psychologist in the Department of Psychological Science at the University of California, Irvine. Her research focuses on understanding the causes and consequences of antisocial risk-taking and illegal behavior during adolescence.

Emily Kan is a doctoral student in the Department of Psychological Science at the University of California, Irvine. Her research interests include adolescent and young adult substance use in a legal context.

Cortney Simmons is a Postdoctoral Researcher at Yale University. Her research broadly focuses on juvenile delinquency and adolescent development within the context of the juvenile justice system.

Dustin Pardini is an Associate Professor in the School of Criminology and Criminal Justice at Arizona State University. Pardini's research focuses on the precursors and outcomes associated with the development of antisocial (e.g., violence, theft) and substance using behaviors from childhood to adulthood, as well as evaluating the impact that early psychosocial interventions can have on these problems

Monica Peniche is a graduate student in the Department of Psychological Science at the University of California, Irvine. She is interested in the study of delinquent youth and the interaction of the justice system with youth criminality outcomes.

Paul J. Frick is a Professor in the Department of Psychology at Louisiana State University. His research investigates the many interacting causal factors that can lead children and adolescents to have serious emotional and behavioral problems.

Laurence Steinberg is a Distinguished University Professor and Laura H. Carnell Professor of Psychology at Temple University. His research interests include adolescent brain, behavioral, and psychosocial development; parent-child relationships; developmental psychopathology; juvenile justice; implications of developmental research for legal and social policy.

Elizabeth Cauffman is a Professor in the Department of Psychological Science at the University of California, Irvine. Her research interests include adolescent development, mental health, juvenile justice, and legal and social policy. 